\title{
Measuring carbon emissions from low carbon cities in rapidly urbanising countries - Nepal
}

Roz Price

Institute of Development Studies

15 September 2021

\section{Question}

- What is the evidence around investments in low-carbon cities reducing carbon emissions and pollution and other associated benefits in rapidly urbanising contexts?

- Focus on Nepal and other rapidly urbanising developing countries. If possible, include information on and methodologies for measuring carbon emissions associated with cities and benefits of investing in low carbon cities for reducing carbon emissions.

\section{Contents}

1. Summary

2. Low carbon cities

3. Nepal

4. References

The K4D helpdesk service provides brief summaries of current research, evidence, and lessons learned. Helpdesk reports are not rigorous or systematic reviews; they are intended to provide an introduction to the most important evidence related to a research question. They draw on a rapid deskbased review of published literature and consultation with subject specialists.

Helpdesk reports are commissioned by the UK Foreign, Commonwealth, \& Development Office and other Government departments, but the views and opinions expressed do not necessarily reflect those of FCDO, the UK Government, K4D or any other contributing organisation. For further information, please contact helpdesk@k4d.info. 


\section{Summary}

Climate change and urbanisation are inextricably linked. With the acceleration of urbanisation in many developing countries, urban areas play a major role in energy consumption and carbon dioxide emissions. This is true of Nepal, which has experienced rapid urbanisation in recent decades. However, no studies were identified that evaluate the efforts of reducing greenhouse gas (GHG) emissions from low carbon cities in rapidly urbanising developing countries. Although, there is literature out there on this that focuses on developed countries and the Global North, this is outside the scope of this report. Given the rapid nature of this review and its limitations it was not possible to fully answer the question of whether investments in low-carbon cities reduce carbon emissions in rapidly urbanising contexts.

The first section of this report looks at the theory of low carbon cities and touches on some of the methodologies for measuring carbon emissions from cities (and the complexities and difficulties with these). The second section looks at Nepal in more detail, highlighting previous literature which has attempted to quantify emissions from cities in Nepal (namely Kathmandu Valley) and the co-benefits of low carbon investment in Nepal. However, overall, literature was largely limited on these topics, and was often older being from 5 years or more ago. Of note is an emissions inventory for Nepal for 2016 by Sadavarte et al. (2019) - although other literature notes that data on emission characteristics are still limited (IMC Worldwide, 2020). ICLEI (2009) also produced city emissions profiles for 3 Nepalese cities, but these are quite outdated. There are several studies related to low carbon development pathways for major cities in developed countries or China, however such studies from the perspective of emerging cities from the developing world are limited. Research into other developing countries with similar characteristics to Nepal was briefly explored in this rapid review but there was not time to fully explore this literature base. Most of the literature explored is from academia, although some is from non-governmental organisations particularly those looking at engaging cities in climate action (such as C40). The literature explored does not look at gender issues or issues of people with disabilities.

\section{Low carbon cities}

\section{Low carbon societies and cities}

According to A Primer on Low Carbon Societies produced by the International Research Network for Low Carbon Societies [LCS-RNet] (Pandey et al., 2016: 25), "the main components of realizing an [low carbon society] are: 1) decarbonization in power generation, 2) substitution of electricity for direct use of fossil fuels in buildings and industry, and in part for transportation fuels, 3) reduction of energy demands through energy efficient technologies and other substitutions, such as sustainable resource use."

Gouldson et al. (2018) conducted a systematic review of 700 papers focusing on the literature on low-carbon measures in the buildings, transport and waste sectors of cities. The main categories for co-benefits associated with low-carbon cities identified by this review were public health (indoor and outdoor air pollution, indoor environmental quality), employment (productivity), congestion (and time), and inclusion (poverty alleviation and inequality). Areas focused on in relation to low carbon urban development and linked to the above co-benefits include: compact, accessible urban forms; clean and efficient urban transportation options; efficient energy-use in buildings and a local clean energy supply; efficient urban waste management (Broekhoff et al., 2018: 16). 
Rapid population growth offers an opportunity for transit-oriented development, in which attractive residential and commercial neighbourhoods are built up around high-capacity transit stations (The Coalition for Urban Transitions, 2019: 47). Benefits of low carbon development in general includes the following. Low-carbon cities would be much healthier, thanks to massive reductions in waste and pollution of all kinds, especially air pollution. Electrification would decrease much air pollution and noise pollution in cities. Ambitious waste prevention and circular economy strategies and improved collection and management services for solid waste would hugely improve public health: cleaner air, soil and water could reduce the prevalence of diseases (such as cholera, encephalitis, typhoid), while clearing solid waste from waterways could also reduce flooding and remove mosquito breeding grounds (The Coalition for Urban Transitions, 2019: 53).

Despite the acknowledged benefits of low-carbon cities, few countries have made it an organising focus of national policy, though elements have been pursued at both the national and local levels (Broekhoff et al., 2018: 16). It is also acknowledged that there are no zero-carbon cities yet, although there are some success stories (mostly in developed countries) (The Coalition for Urban Transitions, 2019). Furthermore, as Colenbrander et al. (2015: 24) highlights, "Where costs or risks are higher, evidence is lacking or supporting institutions are less developed, policymakers can struggle to make the case for low-carbon investment. This is especially the case in developing world cities where decision-makers struggle to keep up with the pace and scale of change."

Colenbrander et al. (2015) present the economic case for proactive investment in low-carbon development for Palembang in Indonesia. They find that a rapidly growing industrial city in a developing country can reduce emissions by $24.1 \%$ in 2025 , relative to business-as-usual levels, with investments of USD405.6 million that would reduce energy expenditure in the city by USD436.8 million. Emissions from the regional grid could be reduced by $12.2 \%$ in 2025 , relative to business-as-usual trends, with investments of USD2.9 billion that would generate annual savings of USD175million and paying back the investment in 15.2 years (Colenbrander et al., 2015: 28). They further conclude that barriers to low carbon transitions may not be economic but institutional and political.

\section{Urbanisation and greenhouse gas emissions}

The relationship between urbanisation and carbon dioxide $\left(\mathrm{CO}_{2}\right)$ emissions has been investigated extensively in recent years in academic circles. Cities and urban areas are blamed for the majority of global greenhouse gas (GHG) emissions, with estimates putting urban areas and their associated affluence (e.g. lifestyle habits) accounting for $70-80 \%$ of global GHG emissions (Hoornweg et al., 2011: 207; Crippa et al., 2021: 4). Whereas, in contrast, others argue that cities are more environmentally efficient than suburban and rural living at similar levels of affluence. These conflicting views relate to the fundamental issue of how to attribute GHG emissions - whether emissions are the 'responsibility' of those who directly produce them (production-based attribution (also known as a territorial approach)) or those whose consumption drives their production (consumption-based attribution (also known as a carbon footprint)) (Hoornweg et al., 2011: 209; Balouktsi, 2020: 235).

It is generally agreed that $\mathrm{CO}_{2}$ emissions and urbanisation have a positive relationship. However, debates remain about attribution of GHG emissions, how the relationship works and how it varies for different countries, with some arguing it is not always homogenous and that the relationship is more prominent in middle-income countries (see Khoshnevis Yazdi \& Dariani, 2019: 514 for 
more in depth information on these debates). There are also ongoing debates around the compact city argument - that large, compact cities should reduce $\mathrm{CO}_{2}$ emissions per households compared to dispersed cities. Many factors in relation to $\mathrm{CO}_{2}$ emissions and urbanisation (such as economic growth, income levels, urban density) have been explored in the literature (see Khoshnevis Yazdi \& Dariani, 2019 for more information). Another issue is related to looking at the effects of declines in urbanisation on $\mathrm{CO}_{2}$ emissions - McGee and York (2018) find that the effect of growth/decline in urban populations on $\mathrm{CO}_{2}$ emissions is asymmetrical in low and middle income countries, where a decline in urbanisation reduces emissions to a much greater degree than urbanisation increases emissions; arguing that how patterns of migration between rural and urban areas change over time also matter for emissions.

Hasan and Zhang (2020: 3) highlight that "systematic understandings of the interplay between household energy use, carbon emissions, and the environmental footprint of growing cities, especially for cities and peri-urban areas in developing countries remains lacking." Their study quantifies Pakistan's districts' carbon emissions and their changes over time based on a representative household's energy consumption for both urban and rural districts. Their findings reject the compact city hypothesis (which stands true for some US cities) for Pakistan, showing that hotspots for carbon emissions tend to cluster around megacities - Islamabad has the highest per capita carbon emissions at one ton per year. This suggests that the compact city hypothesis may not hold in the urbanising developing countries. They also highlight the importance of accounting for the differences in the contribution of firewood and household waste to urban and rural household carbon emissions in developing countries, as household energy use patterns will adapt as people migrate from rural to urban areas (Hasan \& Zhang, 2020: 3).

Further research has explored how slums may change the relationship between urbanisation and $\mathrm{CO}_{2}$ emissions - in particular the extent to which mitigation efforts can be followed without sacrificing the well-bring of individuals. For example, McGee et al. (2017) explore this relationship in relation to carbon intensity of well-being (CIWB) (measured as a ratio of carbon dioxide emissions and life expectancy). The study, using a Prais-Winsten regression model with panel-corrected standard errors (PCSE), finds that the carbon intensity of well-being in most nations from 1960-2013 varies based on the economic context and whereabouts of a substantial portion of a nation's urban population. Specifically, "the rate of increase in CIWB for countries without substantial slum populations begins to slow down at higher levels of urbanization, however, the association between urbanization and CIWB is much smaller in countries with substantial slum populations" (McGee et al., 2017: 1). They put forth two possible explanations for this relationship (although they do not go into detailed discussion of these). Firstly, a possible explanation for the findings is that "in developing nations with substantial slum populations, urban growth has a smaller association to processes that produce $\mathrm{CO}_{2}$ emissions, such as energy consumption and the manufacturing of impervious surface area, than it does in nations with no slums" (McGee et al., 2017: 5). Secondly, "another possible explanation of the reduced association of urban development on CIWB is that slums are often more densely populated, and have access to less safe and reliable infrastructure than other urban areas, which might lead to reduced resource use and emissions" (McGee et al., 2017: 5). Another important consideration is the other differences in urban development between the countries that have slum populations and those that do not (i.e. not solely just the presence or not of slums). The study "demonstrates the complexity of urban development by finding that there is not a linear relationship between CIWB and urban population growth in developing countries that have slum populations, and in countries that do not fit this specific criterion" (McGee et al., 2017: 7). The present study also 
shows future research into emissions reductions and well-being needs to be mindful of the contrast between urbanisation in developing nations that have slums and other countries.

Khoshnevis Yazdi and Dariani (2019) investigate the relationship between $\mathrm{CO}_{2}$ emissions, energy consumption, real income, trade openness and urbanisation in Asian countries during 1980-2014 using a number of models. They find that "The effect of urbanisation on $\mathrm{CO}_{2}$ emissions are continuous and change in the short and long run. Urbanisation increases resident income, accelerates industrialisation, produces public transit networks or energy-free transport modes and decreases household size, all of which affect $\mathrm{CO}_{2}$ emissions in various ways" (Khoshnevis Yazdi \& Dariani, 2019: 527). They recommend using long- and short- run strategies in the selection and implementation of low-carbon pathways to urbanisation.

\section{Measuring carbon emissions from cities}

Hoornweg et al. (2011) argue that GHG emissions reduction in cities should begin with a GHG inventory to give a good understanding of the sources of emissions to determine where best to direct mitigation efforts. Regular updating is needed to monitor the impact of policy initiatives. However, Hoornweg et al. (2020) also emphasise the difficulties in apportioning responsibility for GHG emissions in urban areas, arguing that these attributions fail to capture the enormous disparities within and across cities - emissions are lowest for poor cities and particularly low for the urban poor. They study the average per capita GHG emissions for 100 cities and highlight that these can vary from more than 15 tonnes of carbon dioxide equivalent $\left(\mathrm{tCO}_{2} \mathrm{e}\right)$ (Sydney, Calgary, Stuttgart and several major US cities) to less than half a tonne (various cities in Nepal ${ }^{1}$, India and Bangladesh) (Hoornweg et al., 2020: 207). The study emphasises the importance of obtaining comparable estimates at the city level and of defining the scope of the analysis (e.g. different levels within a city, apportioning GHG emissions per person). However, gathering emissions information from densely populated areas is complex. The estimated cities' contribution to GHG emissions varies depending on the methods chosen by a given city for compiling its GHG emission inventory (Balouktsi, 2020). Local (country and city) emissions inventories can differ in methodology, sectoral detail and availability of emission time series, which are needed to understand trends and the effectiveness of policy implementation (Crippa et al., 2021: 2). Studies have tried to produce harmonised estimates of emission inventories at a local and global level, for example, Crippa et al. (2021) use the Emissions Database for Global Atmospheric Research (EDGAR) to provide local and global estimates of the evolution of sectorspecific air pollutant and GHG emissions from urban centres over the past 50 years.

Furthermore, "net-zero concepts" used by cities can vary in their precise meaning and applicability (Balouktsi, 2020). Variations in ways of thinking about these concepts can influence urban development as different target interpretations may lead to different responses (Lützkendorf \& Balouktsi 2019 cited in Balouktsi, 2020: 248).

There is an array of methods and protocols to compile a GHG emission inventory for cities. There are three different scopes commonly accepted for urban GHG emissions: 1) direct emissions from sources located within the city boundary (i.e. territorial emissions); 2) indirect emissions that occur as a result of the use of grid-supplied or purchased electricity, heat, steam and/or cooling within the city boundary; and 3) all other indirect emissions (Balouktsi, 2020: 237).

${ }^{1}$ Estimates for Nepal come from ICLEl and are from 1994 
According to Balouktsi (2020: 251)

Over the last decade, the city-scale GHG emission inventory methods have evolved from the Intergovernmental Panel on Climate Change's (IPCC) territorial-based metric to more complex consumption-based estimates of city-induced emissions. However, although the latest accounting protocols include consumption-based accounting, most cities still limit their accounting to [direct emissions from sources within the city and indirect emissions from grid-supplied energy within the city]. Although the increasing exploration of community-wide infrastructure footprint approaches (CIFAs) and consumption-based approaches (CBAs) in the different protocols points to a new trend, the limited number of cities currently undertaking such inventories reveals a need for more detailed and standardised guidelines on how to include [all other indirect emissions], or strengthening the workability of the existing ones.

Balouktsi (2020) explores the differences of three emerging approaches to city-level GHG emissions accounting, based on seven methodological dimensions - three emission inventory/accounting dimensions (boundary-setting, the categorisation of emissions and the type of emissions) and four target setting dimensions (reference unit, use of scenarios, target year and treatment of residual emissions). Each approach can reveal important information which the others fail to identify, suggesting the value of using different and complementary approaches to address as many policy questions and relevant actors as possible in climate action planning. Balouktsi (2020) also proposes a minimum reporting and communication framework that synthesises the considerations explored in the paper and that can act as a first step towards standardising minimum information requirements for a "net-zero" city.

\section{Nepal}

\section{Urbanisation}

The urban population growth rate in Nepal almost doubled from 3.6\% in 1991 to $6.5 \%$ in 2001 (Timsina et al., 2020). According to World Bank statistics Nepal's annual urban population growth rate for 2020 was $3.9 \% .^{2}$ Within Nepal, Kathmandu Valley is growing at $6.5 \%$ per year, with an estimated population of 2.54 million, indicating one of the fastest-growing metropolitan areas in South Asia. The number of urban centres increased from 58 in 2013 to 293 in 2017 (Timsina et al., 2020). Timsina et al. (2020: 3) argue that "the transition of Nepal from predominantly rural to an emerging urban economy is primarily the result of the governmental decisions that merged rural administrative units and designated them as municipalities, administratively the urban units of Nepal." Rural to urban migration is also an important factor. Until 2013, only $17.1 \%$ of Nepal's population resided in 58 designated urban areas, but with the addition of 159 municipalities in 2014/2015, now, 40\% of Nepal's population resides in 217 designated urban areas (MoUD, 2017 cited in Timsina et al., 2020: 6). Furthermore, a major territorial reform in 2017 through the Local Level Restructuring Commission (LLRC) has recommended a total of 753 local level units, of which 293 are declared as urban units (6 Metropolitan Cities, 11 Sub-Metropolitan City and 276 Municipalities), which comprise $56.5 \%$ of the urban population (16.5 million) out of the total population (29.1 million) as of 2019 (CBS, 2019 cited in Timsina et al., 2020: 6). 33.5\% of the urban population is concentrated in 16 urban centres that each has a population of over 100,000

\footnotetext{
2 Information taken from https://data.worldbank.org/indicator/SP.URB.GROW?locations=NP [accessed $15 / 09 / 2021]$
} 
people (MoUD, 2017 cited in Timsina et al., 2020: 7). Urban forms in Nepal are becoming increasingly disorganised, with unplanned land use, shrinking open spaces and haphazard construction, with low quality services. Furthermore, Kathmandu is a "hotspot" of urban air pollution in South Asia due to its unique bowl-shaped structure, surrounded by tall mountains (Mahapatraa et al., 2019).

In Nepal, the smart city concept has entered into discussion among planners and development practitioners since 2016 (Timsina et al., 2020: 16). However, the smart city envisioned by the government of Nepal is an urban development vision to integrate information and communication technology (ICT) in a secure fashion to manage a city's assets (MOUD, 2017 cited in Timsina et al., 2020). It is linked with the aim to cope with disasters as they are "thought to be disaster resilient, eco-friendly and people centric cities" (Timsina et al., 2020: 16). Master plans for Palungtar, Nijgadh, and Lumbini to develop as smart cities were developed in 2016. Altogether 40 growing Nepalese cities have been flagged for priority focus by the government. Kathmandu Valley Development Authority (KVDA) has planned to improve upon the existing urban space within valley into four "smart cities".

\section{Emission estimates for Nepal}

Some literature was identified that provides estimates of Nepal's GHG emissions, although the literature is not as established as might be expected. One paper was identified that calculates the GHG emissions from three of Nepal's main cities, however, this is from 2009. No further cityspecific emissions information could be found in the time given for this review. Other studies explore sector-specific emissions in Nepal, some of these are also highlighted here for information.

It has also been noted in the literature that there is a lack of fine resolution and updated emission inventories for Nepal, which make modelling and estimates more difficult (Mahapatraa et al., 2019). Although Sadavarte et al. (2019) have recently attempted to produce one for Nepal.

\section{City profiles: ICLEI, 2009}

The 'Roadmap of South Asian Cities and Local Governments for the Post 2012 Global Climate Agreement and Actions' project, supported by the British High Commission was a South Asian regional initiative, (under ICLEl's Bali to Poznan to Copenhagen roadmap) led by elected representatives of active South Asian cities, to develop an overall regional approach and consensus for addressing urban climate change (ICLEI, 2009). It collected city energy consumption and related carbon emissions inventory data of 54 South Asian cities. The study followed the principle drawn from WRI/WBCSD/ICLEI GHG Protocol guidelines through a structured feedback process. The equivalent carbon emissions from the selected fuel and energy sources for local governments and community operations were calculated using Harmonised Emissions Analysis Tool (HEAT), a unique and customised emissions calculation tool/software for ULBs/local governments (ICLEI, 2009). The study covers the operations owned by Municipal Corporations as Corporation Level emissions (that includes all the services such as street lighting, water supply system, sewage system, etc.) and the City Level emissions that includes the rest of the city information (such as residential, transportation, commercial, etc). Community and commercial energy profiles are also provided for each city.

Kathmandu city profile (ICLEI, 2009: 67): 
- Population estimate: 0.70 Million (2001)

- Area: $50.67 \mathrm{~km}^{2}$

- City activities contribution: 0.29 Million $\mathrm{tCO}_{2} \mathrm{e}$ annually

- Per capita emissions: 0.12 T/Year in 2007-08.

- Corporation Level Emissions: $0.66 \%$ of total city emissions

\section{Lalitpur city profile (ICLEI, 2009: 68):}

- Population estimate: 0.16 Million (2001)

- Area: $15.43 \mathrm{~km}^{2}$

- City activities contribution: 0.05 Million $\mathrm{tCO}_{2} \mathrm{e}$ annually

- Per capita emissions: 0.33 T/Year in 2007-08.

- Corporation Level Emissions: $0.84 \%$ of total city emissions

Pokhara city profile (ICLEI, 2009: 69):

- Population estimate: 0.18 Million (2001)

- Area: $11.6 \mathrm{~km}^{2}$

- City activities contribution: 0.07 Million $\mathrm{tCO}_{2} \mathrm{e}$ annually

- Per capita emissions: 0.35 T/Year in 2007-08.

- Corporation Level Emissions: $0.23 \%$ of total city emissions

\section{Emissions inventory: Sadavarte et al., 2019}

Sadavarte et al (2019) developed a high resolution $(1 \mathrm{~km} \times 1 \mathrm{~km})$ present-day technology-linked multipollutant emission inventory for Nepal for the base year 2011, exploring the current combustion technologies and sectoral energy consumption. They give estimate emissions of aerosols, trace gases and greenhouse gases from five energy-use sectors (residential, industry, commercial, agriculture and transport) and an open-burning source (agro-residue) for the period 2001-2016, using bottom-up methodologies. Comparison of results with the regional inventory MIX showed lower estimates of Nitrogen Oxides (NOx), carbon monoxide (CO), black carbon $(\mathrm{BC})$, organic carbon $(\mathrm{OC})$ and sulphur dioxide $\left(\mathrm{SO}_{2}\right)$. while methane $\left(\mathrm{CH}_{4}\right)$, nitrous oxide $\left(\mathrm{N}_{2} \mathrm{O}\right)$, non-methane volatile organic compounds (NMVOC) and fine particles $\left(\mathrm{PM}_{2.5}\right)$ were estimated to be higher, due to differences in methodologies, emission factors and the disaggregation of energy across sources and sectors.

Sadavarte et al (2019) estimate that the national total energy consumption in 2011 was 378 PJ with the residential sector being the largest energy consumer $(79 \%)$, followed by the industry (11\%) and transport (7\%) sectors. National GHG emission estimates are given in Table 1 for 2011. Biomass was the dominant energy source contributing $88 \%$ to national total energy consumption, while the share of fossil fuel is only $12 \%$ in 2011 . Biomass contribution to the national total energy consumption had decreased to $84 \%$ and imported fossil fuels increased to $16 \%$ in 2016. The energy consumption at sectoral level was also estimated for each year from 2001-2016, with national total energy consumption of 463 PJ in 2016, a factor 1.62 increase compared to $286 \mathrm{PJ}$ in 2001 . The energy consumed in the residential sector was estimated at $322 \mathrm{PJ}$ in 2016, a factor of 1.32 higher than in 2001. The industry sector consumed $79 \mathrm{PJ}$ of 
energy in 2016, a 3 times increase since 2001. The commercial sector consumed 6.4 PJ of energy in 2016, which is 1.8 times the energy used in this sector in 2001. The transport sector, comprising of both on-road vehicles and off-road tractors and tillers, consumed $45 \mathrm{PJ}$ (with additional 6 PJ in aviation) of energy in 2016, a factor of 4.5 higher than in 2001.

Table 1: National GHG emission estimates for 2011

\begin{tabular}{|l|c|c|c|c|c|c|c|c|c|c|}
\hline & $\mathrm{CO}_{2}$ & $\mathrm{CH}_{4}$ & $\mathrm{~N}_{2} \mathrm{O}$ & $\mathrm{NOx}$ & $\mathrm{CO}$ & $\mathrm{NMVOC}$ & $\mathrm{PM}_{2.5}$ & $\mathrm{BC}$ & $\mathrm{OC}$ & $\mathrm{SO}_{2}$ \\
\hline $\begin{array}{l}2011 \text { national } \\
\text { emissions }\end{array}$ & $\begin{array}{c}8.4 \\
\mathrm{Tg}\end{array}$ & $\begin{array}{c}666 \\
\mathrm{Gg}\end{array}$ & $\begin{array}{c}2.5 \\
\mathrm{Gg}\end{array}$ & $\begin{array}{c}72 \\
\mathrm{Gg}\end{array}$ & $\begin{array}{c}1,984 \\
\mathrm{Gg}\end{array}$ & $477 \mathrm{Gg}$ & $\begin{array}{c}239 \\
\mathrm{Gg}\end{array}$ & $\begin{array}{c}28 \\
\mathrm{Gg}\end{array}$ & $\begin{array}{c}99 \\
\mathrm{Gg}\end{array}$ & $\begin{array}{c}28 \\
\mathrm{Gg}\end{array}$ \\
\hline
\end{tabular}

Source: Author's own. Created using data from Sadavarte et al (2019: 30)

The study also looks at Kathmandu Valley and calculates its energy use as 30 PJ in 2011, which is $8 \%$ of the national energy consumption (378 PJ). In the Kathmandu Valley, the residential sector shares $41 \%$ of the total energy consumption, followed by transport $(26 \%)$, industry $(22 \%)$ and commercial $(10 \%)$, with a small amount in agriculture sector which in comparison do not resemble the national energy consumption pattern across these sectors. In 2016 the Kathmandu Valley consumed 51 PJ of energy which is a factor of 1.7 higher than 2011, with an increase in energy from mainly industry and transport sector. In spite of an increase in population, the residential sector has seen growth in use of energy efficient renewable technologies and cleaner fuels (e.g., LPG) which didn't cause a spike in 2016 energy compared to 2011 . Similarly, the increase in production by co-located point source industries and vehicle registration have led to ramp up the sectoral energy in these two sectors by a factor 3 and 2, respectively.

\section{Kathmandu Valley estimates}

No specific estimates of emission changes due to implementing "low carbon city" frameworks in Nepal were found in this rapid review. The following papers provide some emission reduction scenarios in relation to energy mix for Kathmandu Valley. These studies also emphasise the cobenefits of emission reductions in relation to reduction in local pollutants and improved energy security.

\section{Shrestha et al., 2017}

Shrestha et al. (2017) investigate urban energy scenarios for Kathmandu Valley, in an effort to deal with Nepal's energy crisis (i.e. high dependence on imported fossil fuels and the sluggish development of hydropower for electricity generation). Transportation (48\%) is the sector with the largest consumption of total energy consumption in the urban area of Kathmandu Valley, followed by the household sector (33.2\%), and finally the industrial sector (18.8\%). Shrestha et al. (2017) developed 6 scenarios using the base year of 2015 and based on the urban area of Kathmandu Valley (see paper for further information on the modelling used). ${ }^{3}$ The following was observed:

\footnotetext{
${ }^{3}$ Business As Usual (BAU): The scenario assuming that there will be no change in existing policies; Solar Radiation (SR): It is expected that $25 \%$ of the total energy demand share will be solar energy. The final energy intensity for solar is $274 \mathrm{MJ}$ per year per household; Solid Waste (SW): Involves the conversion of solid waste
} 
- All the proposed scenarios showed an increasing tendency in energy demand but with a different increase rate. The Comprehensive Scenario is the scenario with the lowest increase rate and therefore is considered to be the most plausible scenario.

- The BAU Scenario found that with no change in the current policy, the transportation sector will still lead for the next 20 years in energy consumption in Kathmandu Valley, with a significant increase in its total share in energy consumption from $48 \%$ to $80.9 \%$ by 2035. BAU is predicted to have the highest level of carbon emissions with 10.2 million $\mathrm{tCO}_{2} \mathrm{e}$ in 2035.

- The Comprehensive Scenario, which has properties from all scenarios (except BAU), had the greatest impact. It has the lowest level of carbon emissions with 5.7 million $\mathrm{tCO}_{2} \mathrm{e}$ in 2035. The scenario reduces the energy demand by $32.36 \%$, the GHG emission by $44.12 \%$, and the social cost by $33.79 \%$ compared to BAU. This scenario implies that the Kathmandu Valley authority will support the installation of photovoltaic solar panels, the use of electric vehicles and electric cookers, and convert solid waste into energy.

- The authors recommend prioritising the EV (electric vehicles) Scenario as it had a better performance than the other individual category scenarios. It has two major benefits: lowering the dependency on petroleum, and significant reduction of GHG emission (by $36.27 \%$ compared to BAU).

\section{Shakya, 2016}

Shakya (2016) analysed the GHG mitigation potential in different economic sectors of Kathmandu Valley by using Long-range Energy Planning (LEAP) framework. The study analyses six scenarios: the BAU case and five alternative sectoral low carbon development strategy scenarios. ${ }^{4}$ The BAU scenario considers the energy system development to meet future service

\footnotetext{
into energy. The share of energy resulted from this conversion is expected to be $10 \%$ in 2035 with a final energy intensity of 1095 MJ per household per year; Electric Cooker (EC): Incorporates the use of electric cookers, given the prerequisite that there is an adequate supply of electricity. It is estimated that the share of LPG in cooking will drop from $95 \%$ to $75 \%$ and the energy intensity will drop from 10,096 MJ to 2524 MJ per year, while the share of electricity for cooking increases to $75 \%$ with a final energy intensity of $7572 \mathrm{MJ}$ per household per year; Electric Vehicle (EV): This scenario falls under the transportation sector. It is expected that the share of electric cars in Kathmandu will reach $50 \%$ in 2035, while electric motorbikes will reach only $30 \%$ due to tough competition with petrol motorbikes in energy consumption. The final energy intensity is $1230 \mathrm{KWh}$ per vehicle per year for cars and $244 \mathrm{KWh}$ per vehicle per year; Comprehensive (COMP): Comprehensive scenario borrowing all properties of the other scenarios other than BAU.
}

\footnotetext{
${ }^{4}$ BAU; Industrial sector based "LCS-IND" scenario: The policy measures are considered as gradual fuel switching from emission intensive fossil fuels to cleaner electricity in motive power, process heating and boiler applications. The fuel switching process gradually starts from $10 \%$ in 2020 , attains $25 \%$ in 2025 and finally reaches $50 \%$ by 2030 . In addition fuel efficient technology options would penetrate for those applications starting from $25 \%$ of the conventional technology in 2020 , followed by gradual increased in the share to reach $50 \%$ in 2025 and 100\% by 2030; Residential sector based "LCS-REG" scenario: Gradual fuel switching from less efficient fossil fuels to more efficient electricity in cooking, space heating and water boiling applications. The fuel switching starts from 10\% in 2020, attains $25 \%$ in 2025 and finally reaches $50 \%$ by 2030 . Commercial sector based "LCS-COM" scenario: Gradual fuel switching as above; Transport sector based "LCS-TRN" scenario: Introduction of energy efficient Electric Passenger Vehicles (EV) by gradually replacing conventional fossil fuel based vehicles in different passenger transport modes. The penetration of the electric passenger vehicles consists of $10 \%$ of the share of non-electric vehicles in 2020 , followed by gradual increased in the share to reach $15 \%$ in 2025 and $20 \%$ by 2030 . In addition there will be gradual shift from conventional non-electric vehicles (passenger + freight) to Electrified Mass Transport (EMT) beginning with modal shift of $10 \%$ of the base case non-electric vehicles to EMT in 2020, followed by gradual increased in the share to reach $15 \%$ in 2025 and $20 \%$ by 2030; Agriculture sector based "LCS-AGR" scenario: Fuel switching from fossil fuel based devices to electric devices would take place for irrigation pumping and thrashing applications with penetration of $10 \%$ in
} 
demands at the minimum cost without any GHG emission limiting policy intervention. See Shakya (2016) for more information on modelling and scenarios - the framework includes projected population growth of Kathmandu Valley (with a projected average annual exponential growth rate of $3.5 \%$ per year between $2012-2030$ ). The following was reported:

- The Total Final Energy Consumption (TFEC) is estimated to grow at 6.3\% (i.e., from 40 $P J$ in 2012 to $122 \mathrm{PJ}$ in 2030). There would be fast growth at the rate of $7.3 \%$ in the consumption of imported fossil fuels consisting of petroleum products, LPG and coal during the study period. This indicates that future energy supply will be more and more dependent on the imported fossil fuels. The use of electricity would increase at the rate of $7.8 \%$ and that of the consumption of biomass would increase at an average annual growth rate $2.2 \%$.

- In the base case, annual GHG emissions would increase at annual growth rate of $6.95 \%$ during the study period (i.e., from 4.456 million $\mathrm{tCO}_{2} \mathrm{e}$ in 2012 to 14.946 million $\mathrm{tCO}_{2} \mathrm{e}$ in 2030). This growth rate is higher than the growth rate of TFEC mostly due to increasing share of fossil fuel in the energy mix in the later period. Similarly emission of other local pollutants would grow in the range of $3.01 \%$ (for $\mathrm{PM}_{10}$ ) to $5.32 \%$ (for $\mathrm{CO}$ ) indicating severity of local air pollution.

- Modelled GHG emission reduction potential in industrial sector as compared to the base case is $12.3 \%$ in $2020,28.8 \%$ in 2025 and $54.8 \%$ in 2030 . The reduction of local pollutants under LCS-IND ranges from 3.9\% reduction for $\mathrm{CO}$ to $12.3 \%$ reduction for $\mathrm{SO} 2$ in 2020 as compared to the base case. Similarly in 2030 , the reduction of local pollutants ranges from $22.2 \%$ decrease for $\mathrm{CO}$ to $55.0 \%$ for $\mathrm{SO} 2$

- Modelled GHG emission reduction potential in the residential sector under LCS-REG scenario as compared to the base case is $7.6 \%$ in $2020,19.9 \%$ in 2025 and $38.7 \%$ in 2030. The reduction of local pollutants under residential sector GHG mitigation measures ranges from $0.002 \%$ reduction for $\mathrm{PM}_{10}$ to $13.2 \%$ reduction for NOX in 2020 under LCSREG as compared to the base case. Similarly in 2030 , the reduction of local pollutants ranges from $0.02 \%$ reduction for $\mathrm{PM}_{10}$ to $36.00 \%$ for NOX.

- Modelled GHG emission reduction potential in the commercial sector under LCS-COM scenario as compared to the BAU case is $9.1 \%$ in $2020,22.8 \%$ in 2025 and $45.8 \%$ in 2030. The reduction of the emissions of the local pollutants under LCS-COM ranges from $0.02 \%$ reduction for $\mathrm{PM}_{10}$ to $5.4 \%$ reduction for $\mathrm{SO} 2$ in 2020 as compared to the base case. Similarly in 2030 , the reduction of local pollutants ranges from $0.2 \%$ reduction for $\mathrm{PM}_{10}$ to $31.6 \%$ for $\mathrm{SO} 2$.

- Modelled GHG emission reduction potential in the transport sector under LCS-TRN scenario as compared to the base case is $12.2 \%$ in $2020,18.5 \%$ in 2025 and $25.0 \%$ in 2030. The reduction of local pollutants under the transport sector GHG mitigation measures ranges from $14.2 \%$ reduction for SO2 to $19.0 \%$ reduction for CO in 2020 as compared to the base case. Similarly in 2030 , the reduction of local pollutants ranges from $28.6 \%$ reduction for $\mathrm{SO} 2$ to $38.3 \%$ for $\mathrm{CO}$.

2020, 25\% in 2025 and reaching the share of fuel switch to $50 \%$ by 2030 . In addition there will be introduction of energy efficient technology options begins to penetrate to reach $25 \%$ of the share in 2020 , followed by gradual increased in the share to reach $50 \%$ in 2025 and $100 \%$ by 2030 for the land tilling applications and remaining fossil fuel based irrigation pumping, and thrashing applications. 
- Modelled GHG emission reduction potential in the agricultural sector under LCS-AGR scenario as compared to the base case is $8.2 \%$ in $2020,18.0 \%$ in 2025 and $34.3 \%$ in 2030. The reduction of local pollutants emissions under agriculture sector GHG mitigation measures ranges from $8.2 \%$ reduction for NOX to $10.6 \%$ reduction for $\mathrm{CO}$ in 2020. Similarly in 2030 , the reduction of local pollutants ranges from $34.2 \%$ reduction for NOX to $44.9 \%$ for $\mathrm{CO}$.

Shakya (2016: 153) found that the combined effect of implementing all the sectoral GHG mitigation strategic measures from the five scenarios can reduce $35.2 \%$ of total GHG emissions from energy use as compared to the base case scenario in 2030. The reduction of total local pollutants emissions under application of all measures ranges from $4.77 \%$ reduction for $\mathrm{PM}_{10}$ to $31.71 \%$ for SO2 in 2030 . The estimated demand side technology investment cost of low carbon measures for different sectors ranges from less than USD $1 / \mathrm{tCO}_{2} \mathrm{e}$ for residential sector to USD $99 / \mathrm{CO}_{2} \mathrm{e}$ for transport sector. Co-benefits from the low carbon investments also include significant reduction in emissions of local pollutants and improvement of energy security.

\section{Co-benefits of low carbon investment}

No paper specifically setting out the economic benefits of low carbon growth strategies in Nepal's cities, specifically, were identified in this rapid review. However, literature does highlight the economic impacts of air pollution to health and welfare losses.

A study by the Global Green Growth Institute (GGGI) (2018) reported that $\mathrm{PM}_{2.5}$, which includes dust from construction and carbon particles released from the burning of fossil fuels and operation of vehicles, has risen in Kathmandu to $30.40 \mu \mathrm{g} / \mathrm{m}^{3}$ in 2014 - three times higher than the WHO standard. In 2016, the annual average exposure of $\mathrm{PM}_{2.5}$ in Kathmandu Valley was nearly five times higher than the WHO standard, and more than four times higher than in the entire country (GGGI, 2018). Approximately 9,000 premature deaths occur annually in Nepal as a result of ambient air pollution. In 2013, welfare loss caused by air pollution was reported at US $\$ 2.8$ billion, equal to almost $5 \%$ of the country's GDP. This is equal to around $40 \%$ of the losses and damages caused by the 2015 earthquake, valued at US\$7 billion (GGGI, 2018: 37). $\mathrm{PM}_{10}$ is also a growing problem in Nepal, and is estimated to increase from $2 \%$ in 2005 to $4 \%$ in 2050 due to an increase in the share of fossil fuel transport (GGGI, 2018). The projected rise of $\mathrm{PM}_{2.5}$ will have a major effect on the economy, i.e. healthcare costs will increase, labour productivity will be affected by reduced working days, and crop yields will decrease.

Nepal is also almost entirely reliant on hydro-electric for its electricity generation (95\% of its generating capacity), most of which is 'run of river' (i.e. no storage) (IMC Worldwide, 2020: 3). This leaves the system vulnerable to any future long-term changes in rainfall patterns resulting from climate change, and the impact of that on river flows. Furthermore, installed generation capacity has not kept up with the growing electricity demand $(1,450 \mathrm{MW})$ and the economic loss from load shedding could be as high as US $\$ 1.6$ billion per year (IMC Worldwide, 2020: 3-4).

A UK-aid supported scoping study on the research priorities around low-carbon transport for Nepal was conducted in 2020 (IMC Worldwide, 2020). It identified a series of opportunities and challenges to the development of low carbon transport in Nepal. The study undertook a literature review and interviews. Part of the scoping explored quantifying the social and economic costs and benefits of a low-carbon transport sector. The study highlights the potential benefits for Nepal of moving away from imported petroleum products towards a domestic supply of renewable as improved energy security and reliability of energy supply. Co-benefits from low 
carbon transport are also apparent. Although revenue generated from tax on importation of petroleum products give government significant revenue, but conversely, benefits could accrue from reduced foreign exchange if fuel demand was reduced. The study also explores emissions data and modelling. It finds that whilst national emission inventories are being created, data on emission characteristics of transport sector are limited. There is also a lack of robust and effective tools to inform decision-makers and support the use of effective action. This makes evaluating change and planning pathways for effective reductions in greenhouse gases and improvements in local air pollution difficult (IMC Worldwide, 2020: vi).

The study suggests the following research questions for further research (implying that these have not been answered in the existing literature): What are the social and economic costs and benefits of a move to a low-carbon transport sector? What are the implications for government revenues of a reduction in petroleum based tax revenues or reduction in foreign exchange outflows for petroleum product purchase? What are the characteristics of greenhouse gas emissions in the transport sector? What tools can be developed that are calibrated and validated with local primary data to assess the impact on greenhouse gases of low-carbon transport policies?

\section{References}

Balouktsi, M. (2020). Carbon metrics for cities: production and consumption implications for policies. Buildings and Cities, 1(1), pp. 233-259. DOI: https://doi.org/10.5334/bc.33

Broekhoff, D., Piggot, G. \& Erickson, P. (2018). Building Thriving, Low-Carbon Cities: An Overview of Policy Options for National Governments. Coalition for Urban Transitions. London and Washington, DC. Available at: http://newclimateeconomy.net/content/citiesworking-papers.

Colenbrander, S., Gouldson, A., Sudmant, A. H., \& Papargyropoulou, E. (2015). The economic case for low-carbon development in rapidly growing developing world cities: A case study of Palembang, Indonesia. Energy Policy, 80, 24-35. https://doi.org/10.1016/j.enpol.2015.01.020

Crippa, M., Guizzardi, D., Pisoni, E., Solazzo, E., Guion, A., Muntean, M., ... \& Hutfilter, A. F. (2021). Global anthropogenic emissions in urban areas: patterns, trends, and challenges. Environmental Research Letters, 16(7), 074033. https://doi.org/10.1088/1748-9326/ac00e2

GGGI (2018). Accelerating Implementation of Nepal's Nationally Determined Contribution: National Action Plan for Electric Mobility. Global Green Growth Institute, Seoul, Republic of Korea, April 2018. https://gggi.org/site/assets/uploads/2018/07/GGGI-Nepal_Action-Planfor-Electric-Mobility.pdf

Gouldson, A., Sudmant, A., Khreis, H. \& Papargyropoulou, E. (2018). The Economic and Social Benefits of Low-Carbon Cities: A Systematic Review of the Evidence. Coalition for Urban Transitions. London and Washington, DC.: http://newclimateeconomy.net/content/citiesworking-papers

Hasan, S.M. \& Zhang, W. (2020). "Will Urbanization in Developing Countries Reduce Carbon Emissions? Panel Data Evidence from Pakistani Household Surveys." Economics Working Papers: Department of Economics, lowa State University. 20023.

https://lib.dr.iastate.edu/econ_workingpapers/118 
Hoornweg, D., Sugar, L., \& Trejos Gómez, C. L. (2011). Cities and greenhouse gas emissions: moving forward. Environment and urbanization, 23(1), 207-227. https://doi.org/10.1177/0956247810392270

ICLEI. (2009). Energy and Carbon Emissions Profiles of 54 South Asian Cities. ICLEI South Asia and British High Commission New Delhi. https://e-lib.iclei.org/wpcontent/uploads/2015/04/Energy-and-Carbon-Emissions-Profiles-for-54-South-AsianCities.pdf

IMC Worldwide. (2020). Country scoping of research priorities on low carbon transport in Nepal. PMU for High Volume Transport (HVT). http://transport-links.com/download/countryscoping-of-research-priorities-on-low-carbon-transport-in-nepal/

Khoshnevis Yazdi, S., \& Golestani Dariani, A. (2019). CO 2 emissions, urbanisation and economic growth: evidence from Asian countries. Economic research-Ekonomska istraživanja, 32(1), 510-530.

https://hrcak.srce.hr/index.php?show=clanak\&id_clanak_jezik=332510

Mahapatra, P. S., Puppala, S. P., Adhikary, B., Shrestha, K. L., Dawadi, D. P., Paudel, S. P., \& Panday, A. K. (2019). Air quality trends of the Kathmandu Valley: A satellite, observation and modeling perspective. Atmospheric environment, 201, 334-347. https://doi.org/10.1016/j.atmosenv.2018.12.043

McGee, J.A. \& York, R. (2018). Asymmetric relationship of urbanization and CO2 emissions in less developed countries. PLOS ONE 13(12): e0208388.

https://doi.org/10.1371/journal.pone.0208388

McGee, J.A., Ergas, C., Greiner, P.T. \& Clement, M.T. (2017). How do slums change the relationship between urbanization and the carbon intensity of well-being? PLOS ONE 12(12): e0189024. https://doi.org/10.1371/journal.pone.0189024

Pandey, R., Kainuma, M., Ishikawa, T. \& Nishioka, S. International Research Network for Low Carbon Societies [LCS-RNet]. (2016). A Primer on Low Carbon Societies. Hayama: Institute for Global Environmental Strategies (IGES). https://lcsrnet.org/pdf/publications/lcs_Primer_on_Low_Carbon_Societies_e.pdf

Sadavarte, P., Rupakheti, M., Bhave, P., Shakya, K., and Lawrence, M. (2019). Nepal emission inventory - Part I: Technologies and combustion sources (NEEMI-Tech) for 2001-2016, Atmos. Chem. Phys., 19, 12953-12973, https://doi.org/10.5194/acp-19-12953-2019

Shakya, S.R. (2016). Benefits of low carbon development strategies in emerging cities of developing country: A case of Kathmandu. Journal of Sustainable Development of Energy, Water and Environment Systems, 4(2), 141-160. http://dx.doi.org/10.13044/j.sdewes.2016.04.0012

Shrestha, M. E., Sartohadi, J., Ridwan, M. K., \& Hizbaron, D. R. (2017). Urban Energy Scenario: the Case of Kathmandu Valley. Journal of Engineering \& Technological Sciences, 49(2). https://doi.org/10.5614/j.eng.technol.sci.2017.49.2.4

The Coalition for Urban Transitions. (2019). Climate Emergency, Urban Opportunity: How national governments can secure economic prosperity and avert climate catastrophe by transforming cities. The Coalition for Urban Transitions.

https://urbantransitions.global/en/publication/climate-emergency-urban-opportunity/

Timsina, N.P., with input from Shrestha, A., Poudel, D.P. \& Upadhyaya, R. (2020). Trend of urban growth in Nepal with a focus in Kathmandu Valley: A review of processes and drivers of change. Tomorrow's Cities Working Paper 001. https://doi.org/10.7488/era/722 


\section{Suggested citation}

Price, R.A. (2021). Measuring carbon emissions from low carbon cities in rapidly urbanising countries - Nepal. K4D Helpdesk Report 1045. Institute of Development Studies. DOI:10.19088/K4D.2021.142

\section{About this report}

This report is based on six days of desk-based research. The K4D research helpdesk provides rapid syntheses of a selection of recent relevant literature and international expert thinking in response to specific questions relating to international development. For any enquiries, contact helpdesk@k4d.info.

K4D services are provided by a consortium of leading organisations working in international development, led by the Institute of Development Studies (IDS), with the Education Development Trust, Itad, University of Leeds Nuffield Centre for International Health and Development, Liverpool School of Tropical Medicine (LSTM), University of Birmingham International Development Department (IDD) and the University of Manchester Humanitarian and Conflict Response Institute (HCRI).

This report was prepared for the UK Government's Foreign, Commonwealth \& Development Office (FCDO) and its partners in support of pro-poor programmes. Except where otherwise stated, it is licensed for non-commercial purposes under the terms of the Open Government Licence v3.0. K4D cannot be held responsible for errors or any consequences arising from the use of information contained in this report. Any views and opinions expressed do not necessarily reflect those of FCDO, K4D or any other contributing organisation.

(C) Crown copyright 2021. 